\section{BLOOD GROUPS AND BLOOD TRANSFUSION.}

By Alexander S. Wiener. Baillière, Tindall \& Cox. 1935. Price 18/-.

Dr. A. S. Wiener has placed the English reading medical profession as a whole under a debt of gratitude by bringing together in one volume all that has been learned within recent years regarding the individual differences and similarities of the blood and the application of this knowledge in diagnosis and treatment. The various blood groups, their relative frequency, the racial variations, the hereditary influences and the causes of their incompatability, as well as the technique of blood grouping and the difficulties and fallacies in the process, are minutely detailed.

The use of blood grouping in the therapeutic measure of blood transfusion, as well as the technique of this latter operation, receive adequate attention. The discussion of the various conditions in which this method of treatment has been tried and in which it is really of benefit is of particular interest, and is one which in our opinion was much needed. Wiener concludes that loss of blood from hæmorrhage, shock and anæmia are the only conditions in which striking and definite results are obtained.

The genetic and anthropological variations in the blood groupings and the significance of these in medico-legal work receives full and detailed consideration and this we consider one of the most valuable sections of the book.

The bibliography is full, the index is adequate, the printing is clear and the whole format of the volume pleasant, so that we are confident that all medical men will find it a useful addition to their library.

\section{AIDS TO SURGERY}

\section{6th Edition.}

By Joll and Ledle. Baillière, Tindall \& Cox. 1935 . Price 7/6.

The authors have succeeded in presenting in a small volume the main facts of surgery. The text is readable and well arranged. An added attraction in this edition is the illustrations which are clear and helpful. The book will prove of value to students during revision of their surgical knowledge prior to qualification and it can be recommended to the post-graduate who desires a survey of surgery.

A very pleasing feature of the book is the discussion of prognosis in certain diseases and it is obvious that the authors are speaking from personal observations made on large series of cases. We note with satisfaction the statement that gastrojejunostomy has very limited value in the treatment of gastric ulcer and a plea for partial gastrectomy in those cases which do not respond to medical treatment. The authors point out the sound pathological basis on which the Miles abdomino-perineal operation for carcinoma of the rectum is based and show that the 5 year survival rate is 60 per cent. This is most encouraging. We feel that the authors are a little too optimistic when they state that the 5 year survival rate for carcinoma localized in the breast is 90 per cent. We are not in complete agreement that metastases preclude the operation of partial gastrectomy in carcinoma of the stomach, for in our experience we have found that patients live longer after this operation and in comfort even though metastases are present. The book is certain to enjoy a wide sphere of usefulness to student and post-graduate and we recommend it to both.

\section{Fellowship Examination Papers, for the Diplomas of the Royal College of Surgeons, Edinburgh, r93I-r935.}

E. \& S. Livingstone, Edinburgh. 1935. Price 2s. 6d.

This compilation of examination questions fulfils a need for candidates for Edinburgh examinations. The book contains all the questions set for four years for the Single Licence, Fellowship and Optional examinations, so that candidates can rapidly survey the requirements of the examiners. A candidate for any of the Edinburgh examinations would be well advised to work through the appropriate sets of questions. 